\section{ANKYLOSING SPONDYLITIS}

By F. Hernaman-Johnson, M.D., F.F.R., D.M.R.E., and W. Alexander LAW, O.B.E., M.D., F.R.C.S. Pp. viii +200 , with 41 illustrations. London: Butterworth \& Co. 1949. 25 s.

This book serves a useful purpose by showing the common clinical pictures produced by the milder degrees of ankylosing spondylitis, and covers the differential diagnosis well except for the fact that it does not mention recurrent attacks of fibrositis which often provide a differential diagnosis.

The authors take a great deal of trouble to provide a comprehensive list of references on this subject, and the orthopaedic side is very well done by Mr. Alexander Law. One feels, however, that the diagnostic side in Part I has a lot of padding and the therapeutic side of Part I has a very definite detail bias in favour of radiotherapy by the author, the late Dr. Hernaman-Johnson who was, of course, a very distinguished radiotherapist.

It is surprising to find that the use of mobilizing exercises for the spine and breathing exercises is covered in the course of less than a page of this book. As these are generally regarded as most important measures in prevention of deformity it seems inadequate. The relief of symptoms by the use of deep heat in the form of shortwave diathermy, so commonly employed with success, is also relegated to one paragraph.

On the whole it would seem that the clinical description and the method of writing this is well done and the surgical angle is also a valuable contribution to the literature on this disease.

\section{MODERN PRACTICE IN ANAESTHESIA}

Edited by Frankis T. Evans, M.B., B.S., F.F.A.R.C.S., D.A. Pp. xx + 566, with 227 illustrations. London: Butterworth and Co. 1949. 50 .

If there is such a thing as 'London Anaesthesia' this handsome book expounds it. A group of experienced anaesthetists working in that locality cover between them the whole field of clinical anaesthesia. They stress the practical side of the subject and avoid becoming involved too much in its scientific bases. The choice of authors was evidently dictated by the experience they had of the subject under their name; the editor himself writes on 'Spinal Anaesthesia' and 'Anaesthesia in Genito-Urinary Surgery,' C. J. M. Dawkins on 'Epidural '; J. K. Hasler on 'Posture ' and George Edwards on 'Rectal Anaesthesia.' All these chapters and many others are excellent. The same principle might with advantage have been extended to the chapters on physiology and chemistry, which, though factual, lack the spirit which only those trained and actively working in such subjects can bring. A particularly good chapter by Blair Gould on the volatile anaesthetic bases contains an ex- ̊ cellent discussion on the present position of cyclo- $?$ propane. His view confirms the impression now $\underset{\mathbb{Q}}{\stackrel{2}{2}}$ gaining ground that far from being the last word in $c$ anaesthesia, cyclopropane is receding in importance $\vec{\Rightarrow}$ and usefulness. The last half of the book is devoted $\stackrel{?}{\rightarrow}$ to the anaesthetic problems met with in special $\overline{0}$ types of surgery. There are, for example, chapters $\frac{\sigma}{\sigma}$ on anaesthesia for neurosurgery, cleft palate repair, $\overline{\bar{\omega}}$. bronchoscopy, dental , surgery, diabetes, heart $\vec{\Phi}$ disease and in the asthmatic. Each author tries to $\propto$ give a complete clinical account of his subject, but $\stackrel{\infty}{\infty}$ naturally, prominence is given to those methods $\vec{\circ}$ which he prefers; hence the suggestion that an appropriate title might have been 'London Anaesthesia.'

The book is the most important post-war textbook of anaesthetics published in this country and 3 . is highly recommended to all interested in the $\tilde{N}$ subject. The publishers may rest content that the iv high standard of the Modern Practice series has $\stackrel{\omega}{\omega}$ been maintainer.

W.W.M.

\section{GREEN'S MANUAL OF PATHOLOGY}

Revised by H. W. C. Vines, M.A., M.D. I7tK Edition. Pp. viii +1200 , with 730 illustration and 12 plates. London: Bailliere, Tindall ane Cox. 1949. 42s.

Professor Vines in a short preface discusses with much insight the several factors which are tending to change pathological teaching and textbooks. It is perhaps surprising that he has made little attempt at the thorough rewriting which this book, like so many of its vintage, now calls for. A few recent productions have gone some way towards the modernization Professor Vines prophesies; all the textbooks of earlier origin, patched and repatched though they may be, bear traces of that necessary formative period when descriptive morbid anatomy was an end in itself. Within these limits this is a sound book, clearly written and well balanced, and it is not often seriously out of date (though 'epithelioma' as a name for squamous carcinoma and gastro-enterostomy as a routine treatment for gastric ulcer, unimportant in themselves, are examples of a frequent need for the broom in odd $D$ corners). Fig. 49, called gout, is a rheumatoid nodule, which may occur in gout but is not its characteristic lesion, and lysol is not a commercial grade of carbolic acid, but errors of this sort are infrequent. The illustrations are excellent, in many ways the best thing in the book; they are technically good enough to stand up to a rather small average size of block and are aptly chosen. Production is good (though the weight is excessive) and the whole book is without doubt value for money. But Professor Vines should have the courage of his prefaced convictions and make the 18 th edition a new book. 